Supporting Information

\title{
Naphthalene Endoperoxide Heterodimer Designed for Sustained Singlet Oxygen Release
}

Ziang Liu, Hao Wu, Jin Li, Lei Wang,* Engin U. Akkaya*

State Key Laboratory of Fine Chemicals and Department of Pharmaceutical Sciences, Dalian

University of Technology, 2 Linggong Road, 116024, Dalian, China.

Table of Contents

NMR spectra

S2-S8

MS Spectra of key intermediates

S9

Time evolution of ${ }^{1} \mathrm{H}$ NMR spectra of compounds $\mathbf{4}$ and $\mathbf{7}$

S10-S11

Rate calculations for figures 5 and 6

$\mathrm{S} 12$ 


\section{NMR spectra}

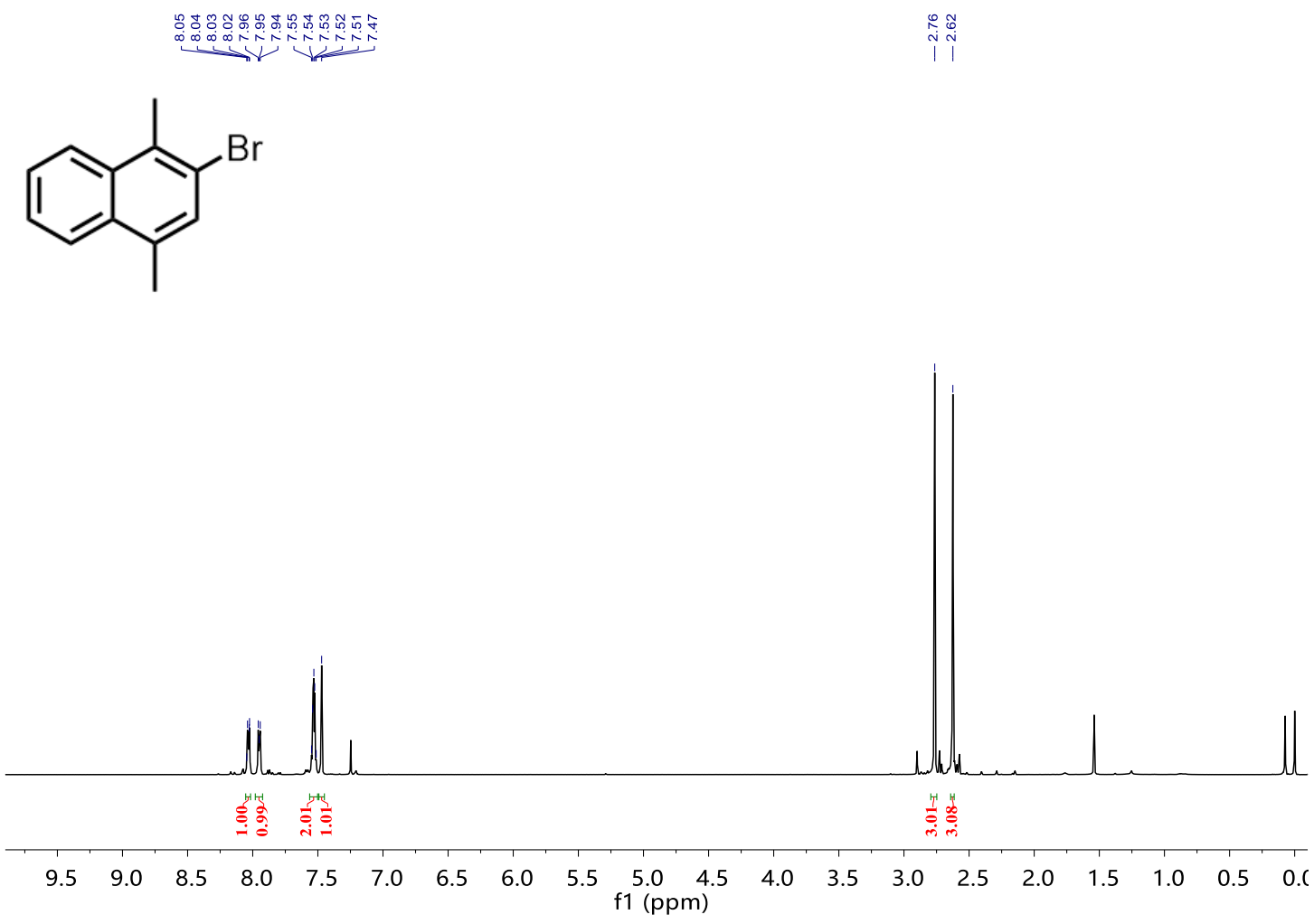

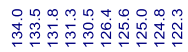

然,

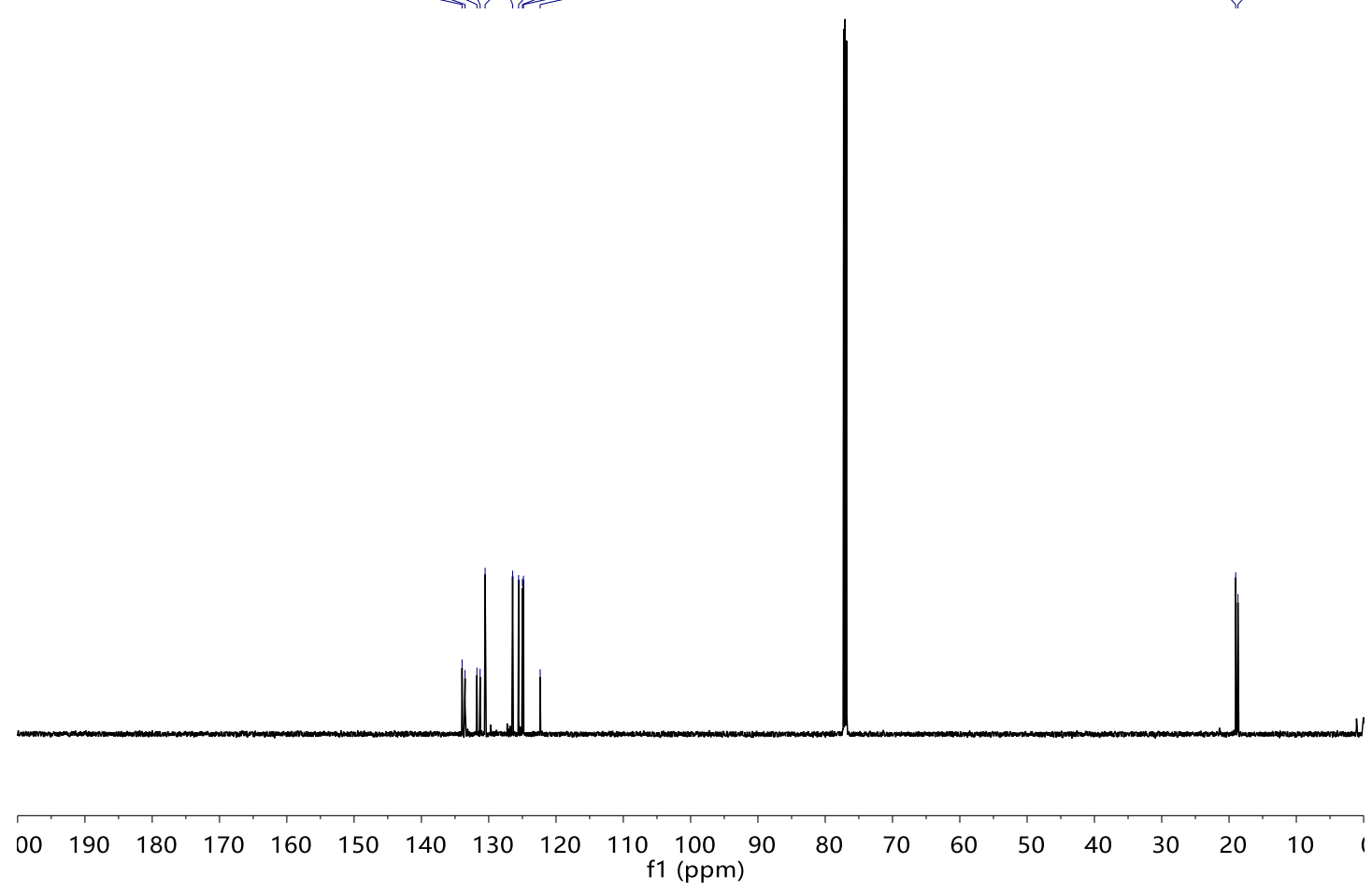

Figure S1. ${ }^{1} \mathrm{H}$ and ${ }^{13} \mathrm{C}$ NMR spectra of compound 2 . 

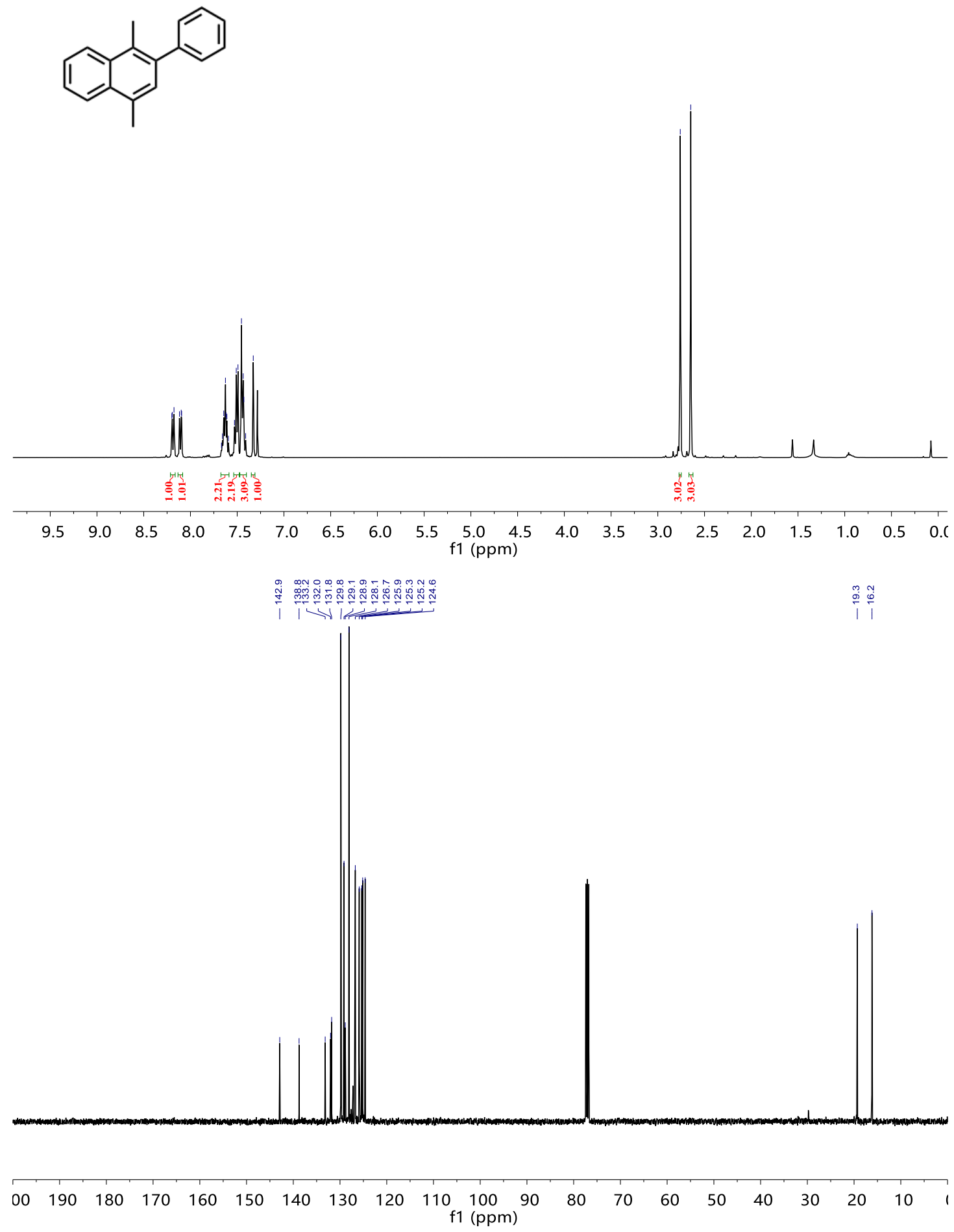

Figure S2. ${ }^{1} \mathrm{H}$ and ${ }^{13} \mathrm{C}$ NMR spectra of compound 3. 

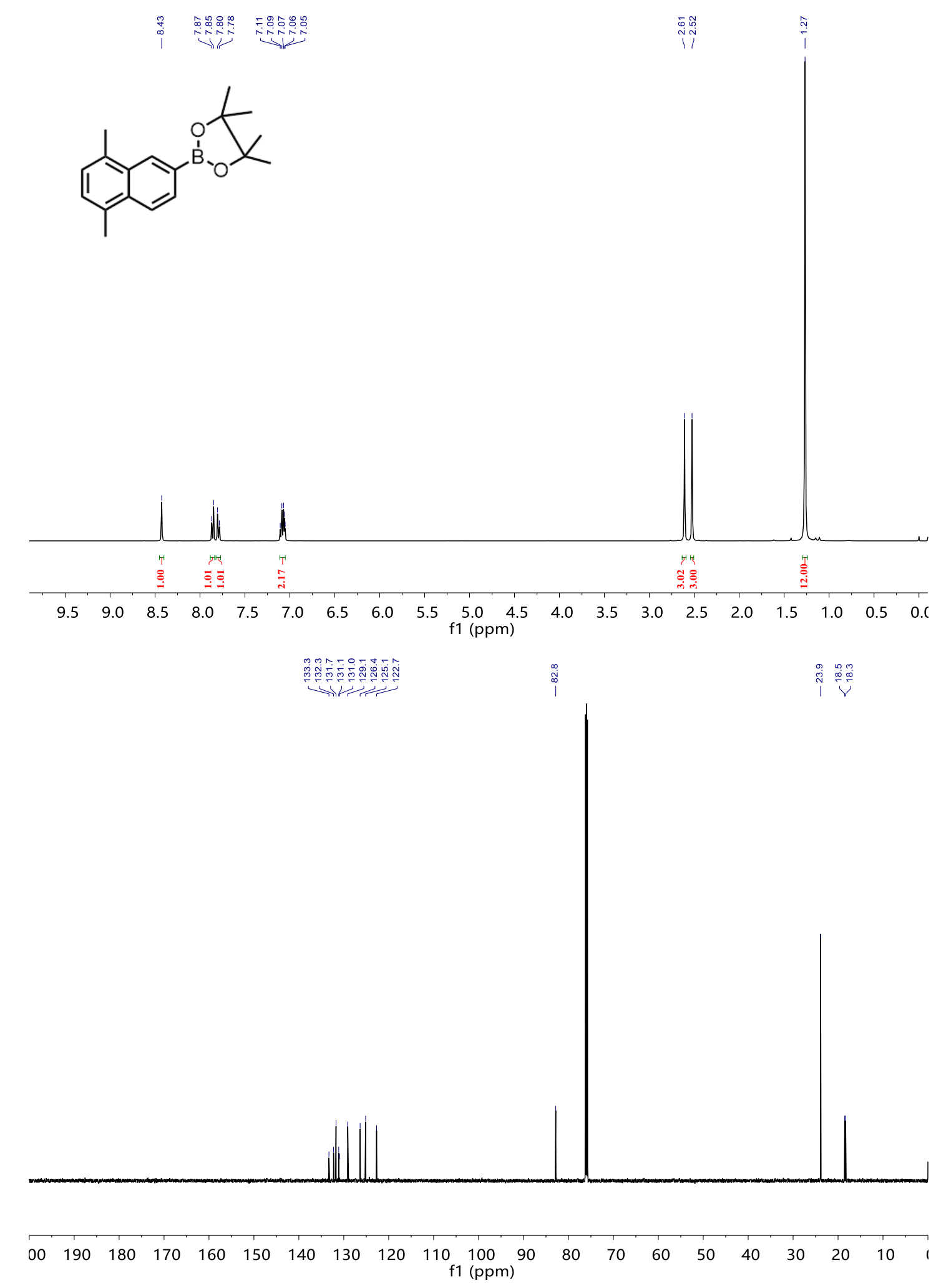

Figure S3. ${ }^{1} \mathrm{H}$ and ${ }^{13} \mathrm{C}$ NMR spectra of compound 5 . 


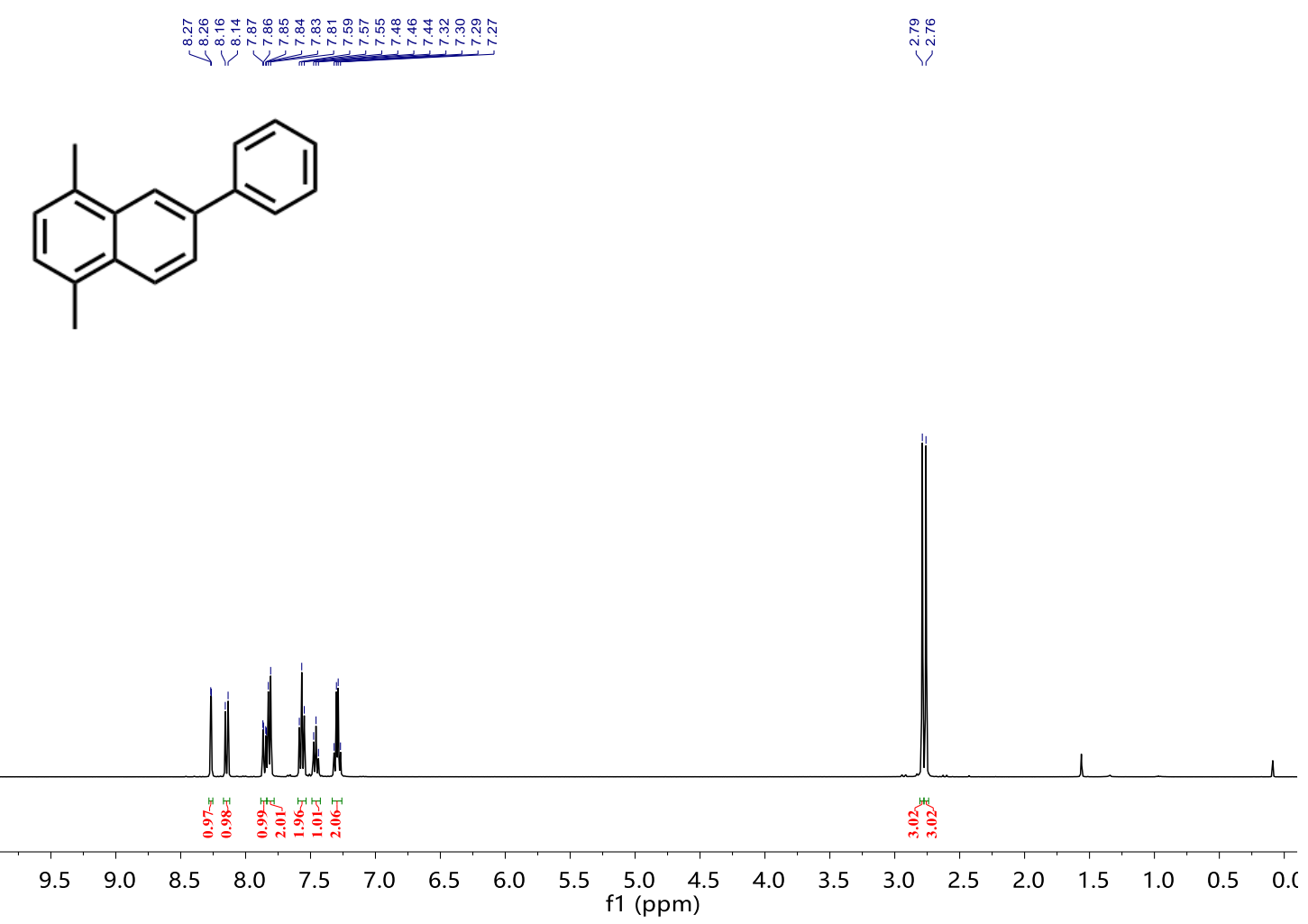

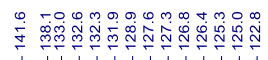

1 人,
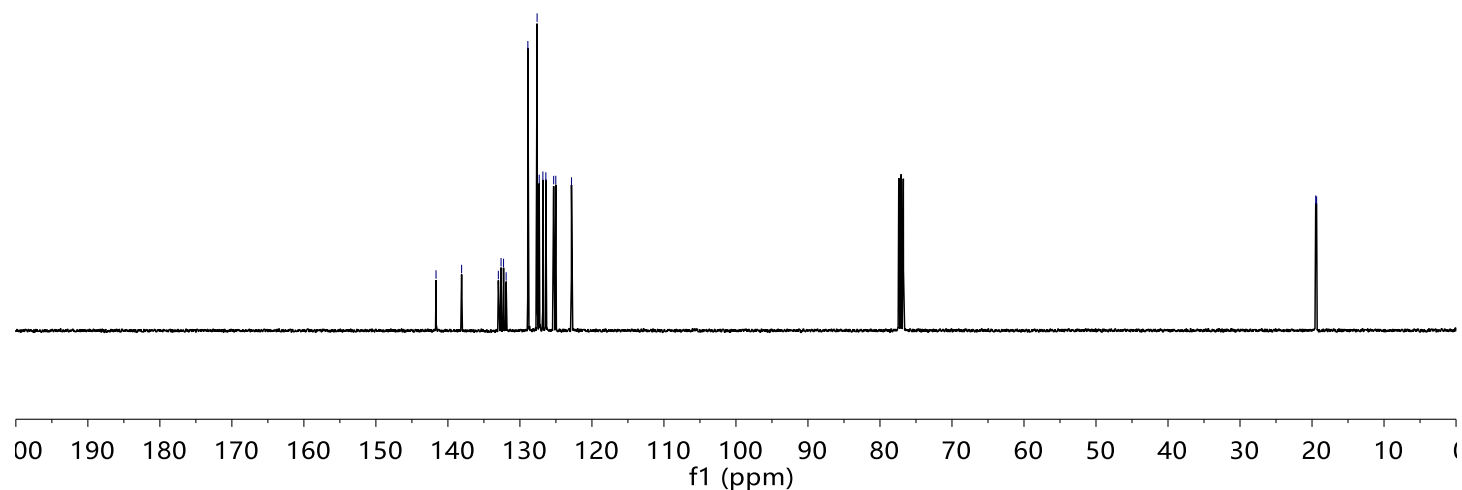

Figure S4. ${ }^{1} \mathrm{H}$ and ${ }^{13} \mathrm{C}$ NMR spectra of compound $\mathbf{6}$. 
<smiles>Cc1ccc(C)c2cc(-c3cc(C)c4ccccc4c3C)ccc12</smiles>

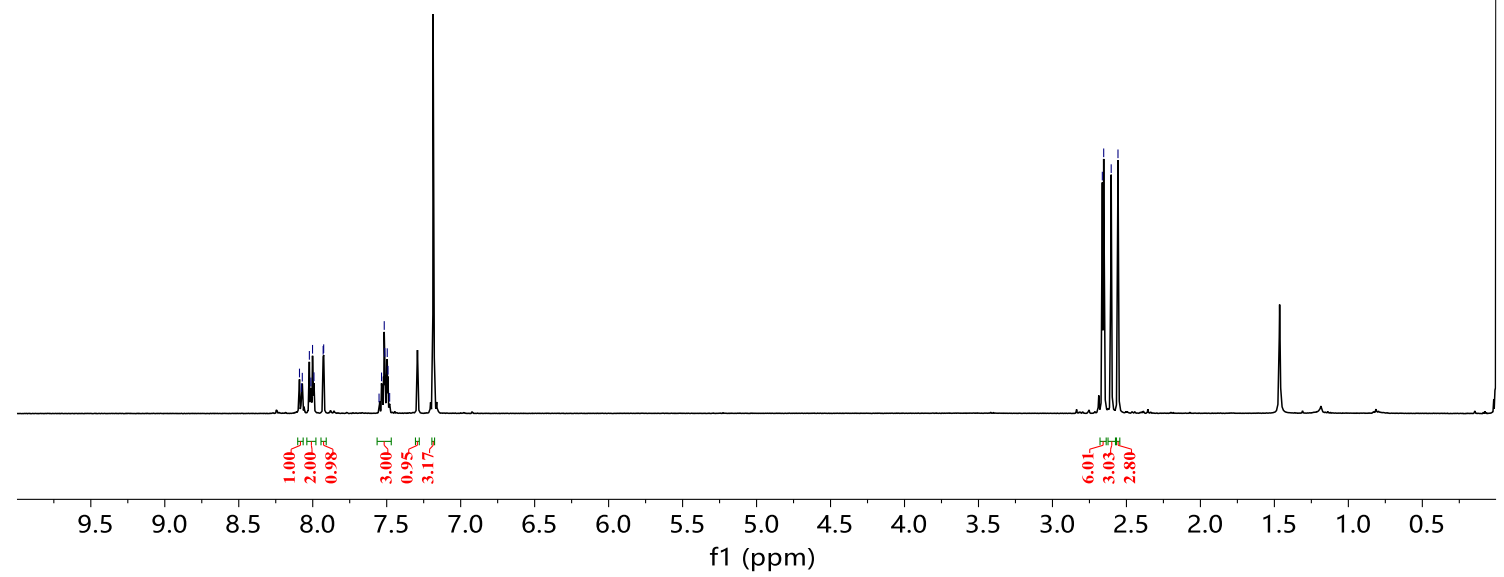

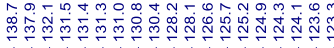

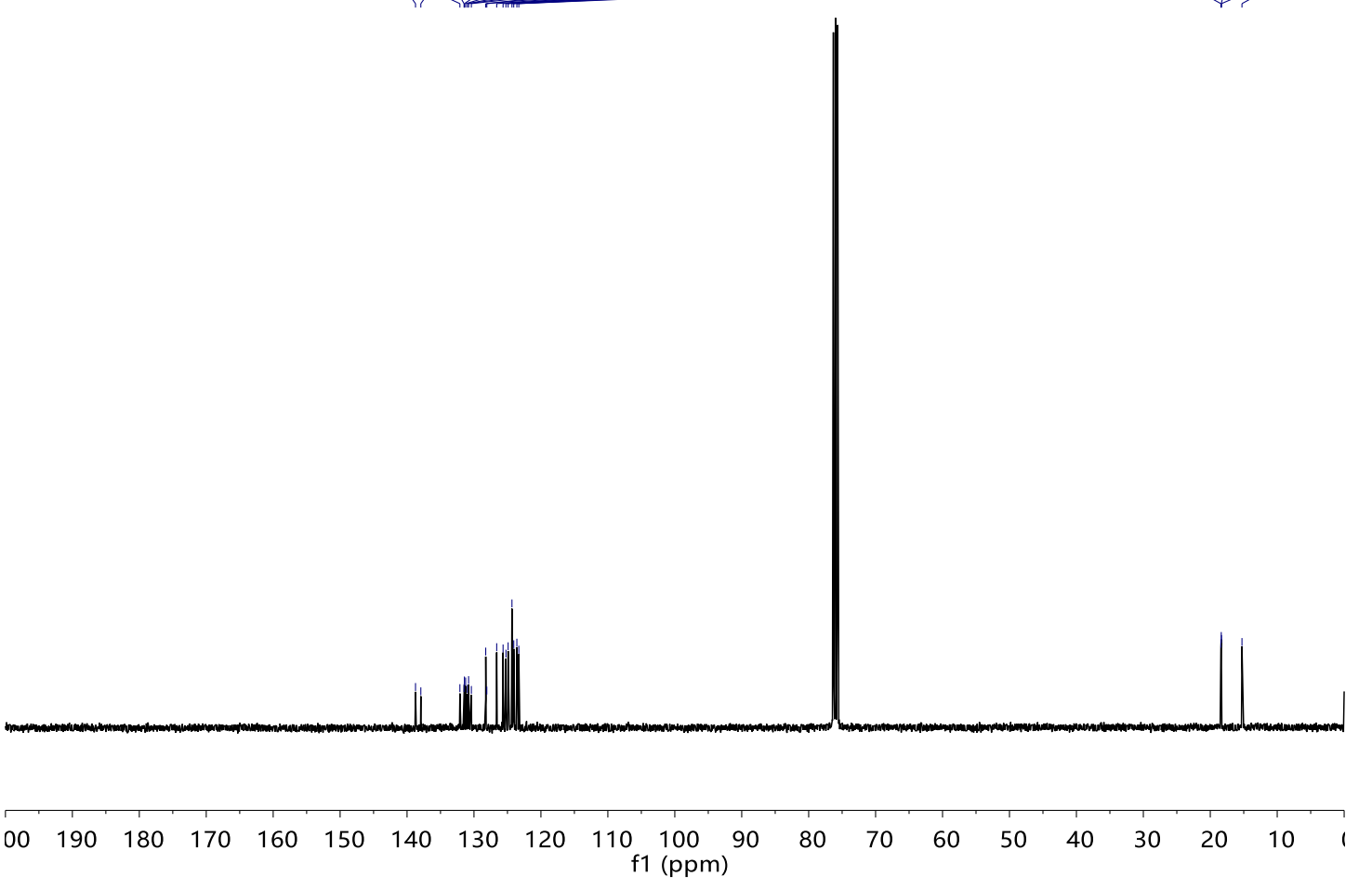

Figure S5. ${ }^{1} \mathrm{H}$ and ${ }^{13} \mathrm{C}$ NMR spectra of compound 8 . 


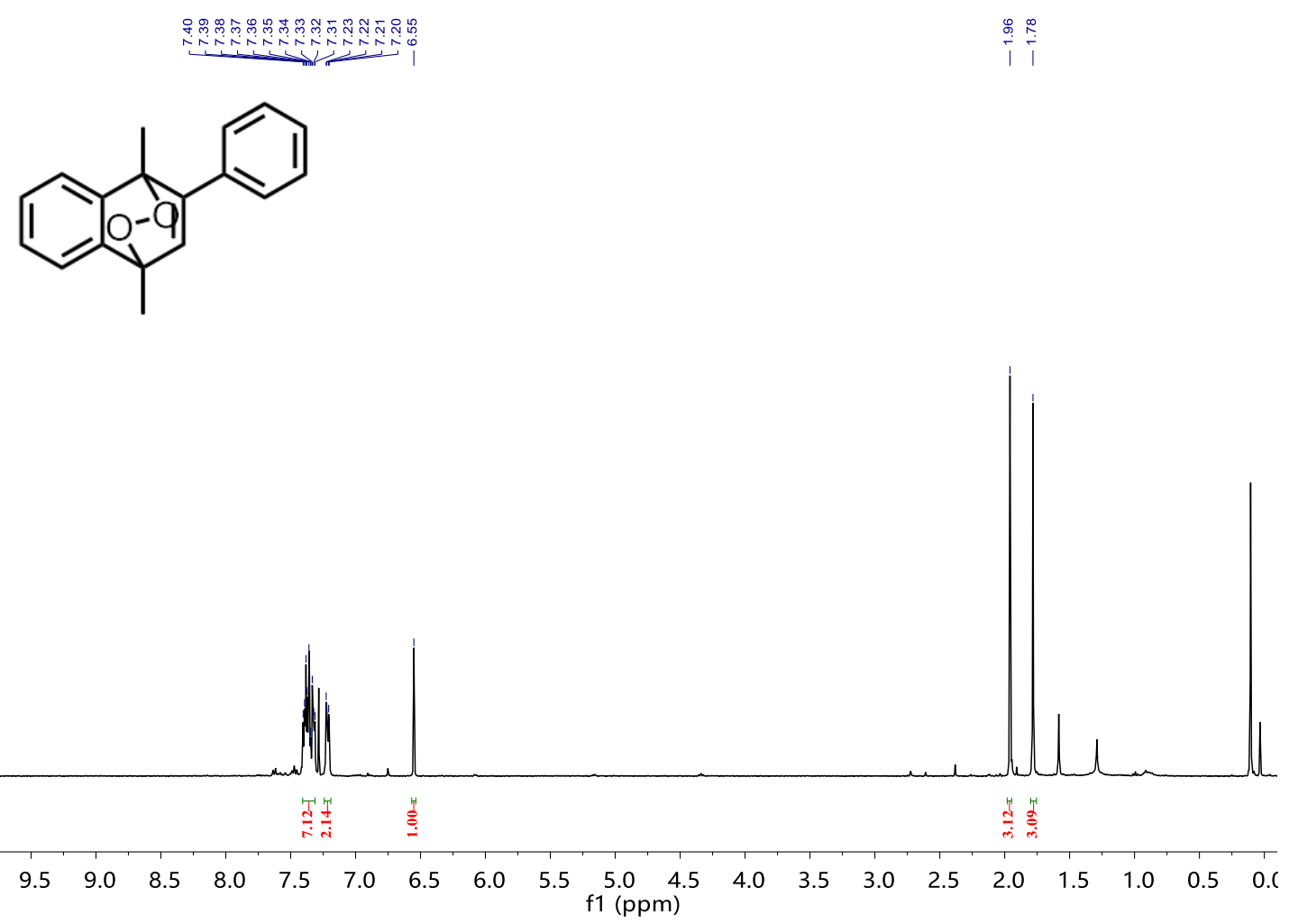

Figure S6. ${ }^{1} \mathrm{H}$ NMR spectrum of compound 4.
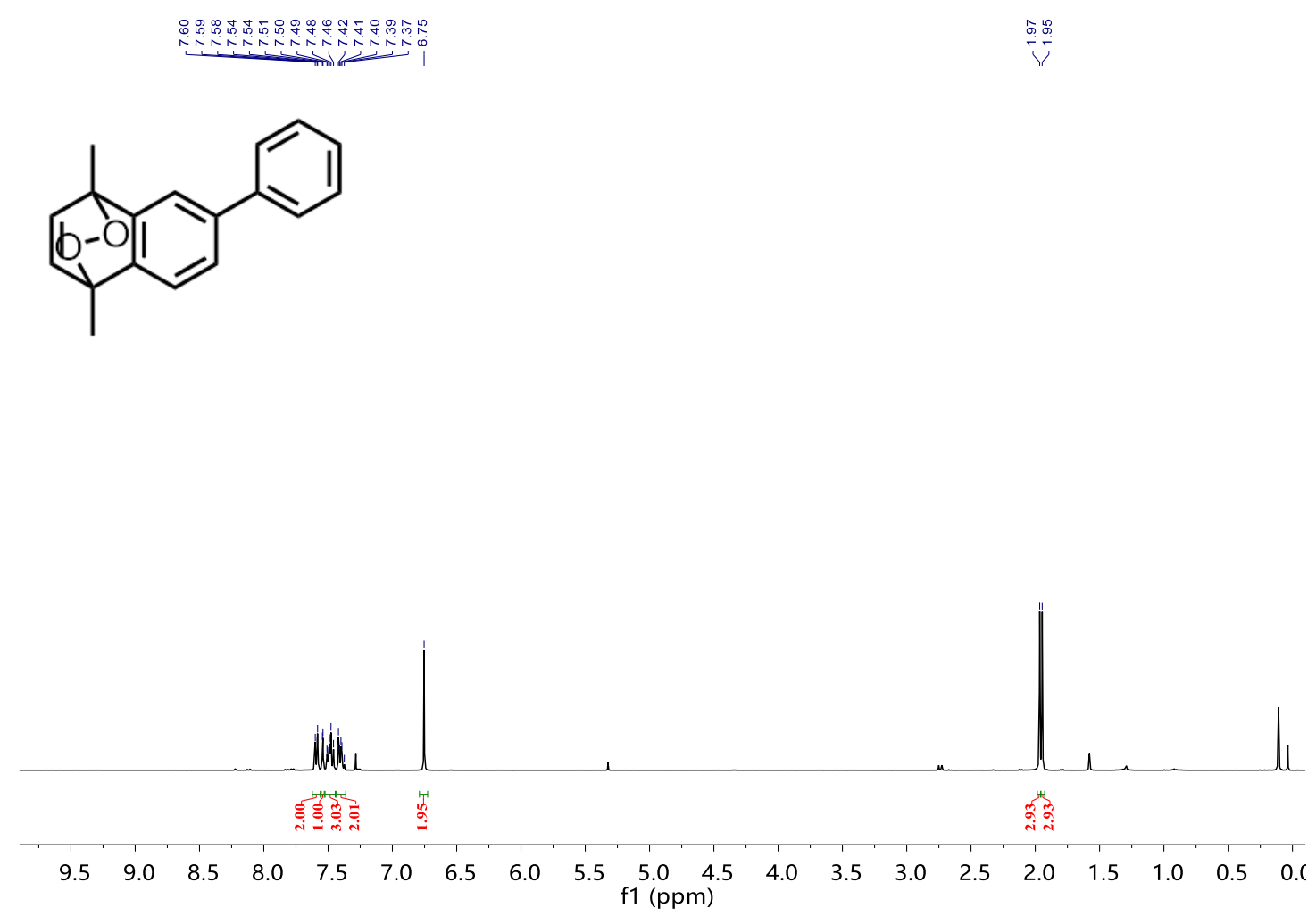

Figure S7. ${ }^{1} \mathrm{H}$ NMR spectrum of compound 7. 


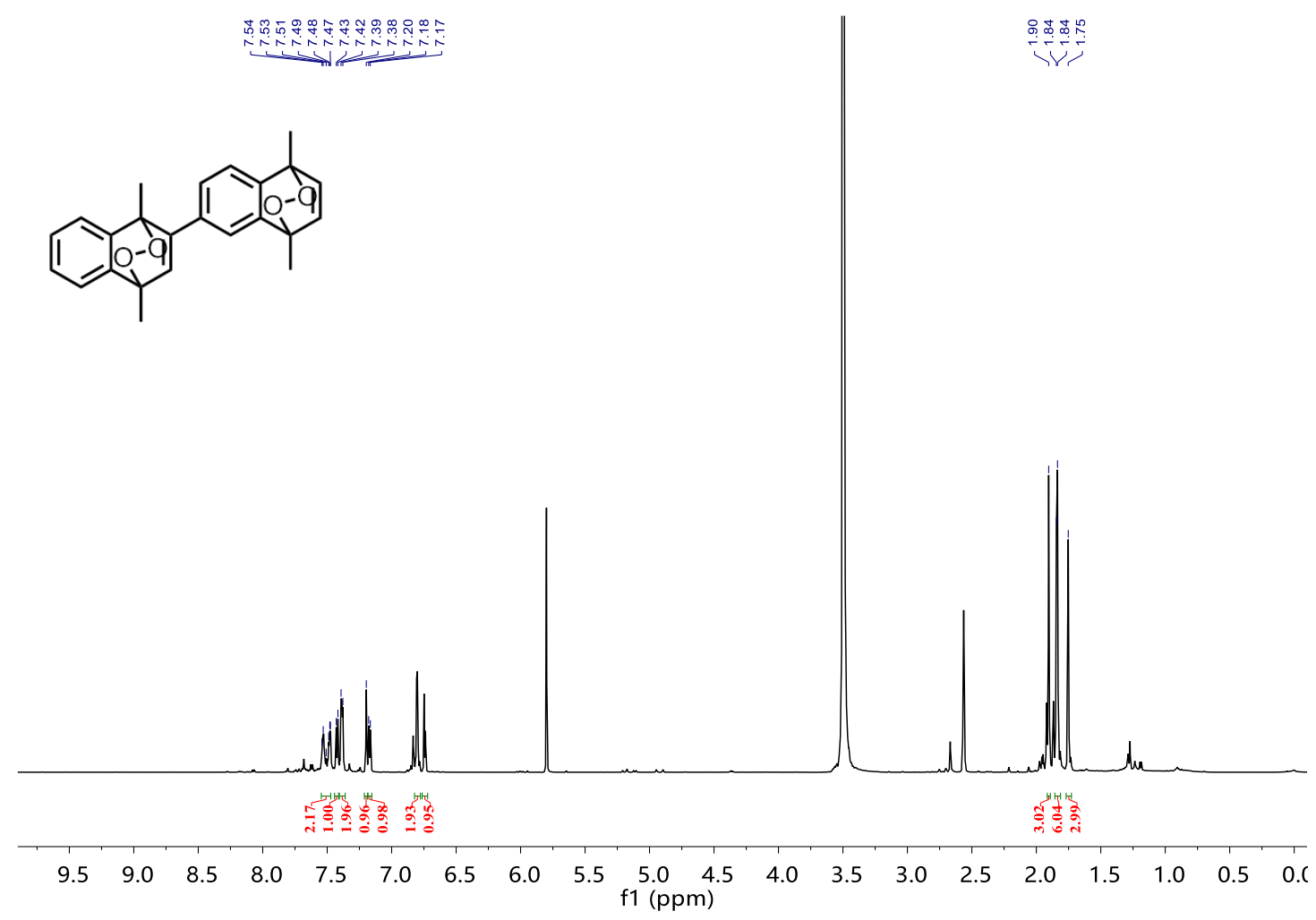

Figure S8. ${ }^{1} \mathrm{H}$ NMR spectrum of compound 9. 
MS Spectra of key intermediates

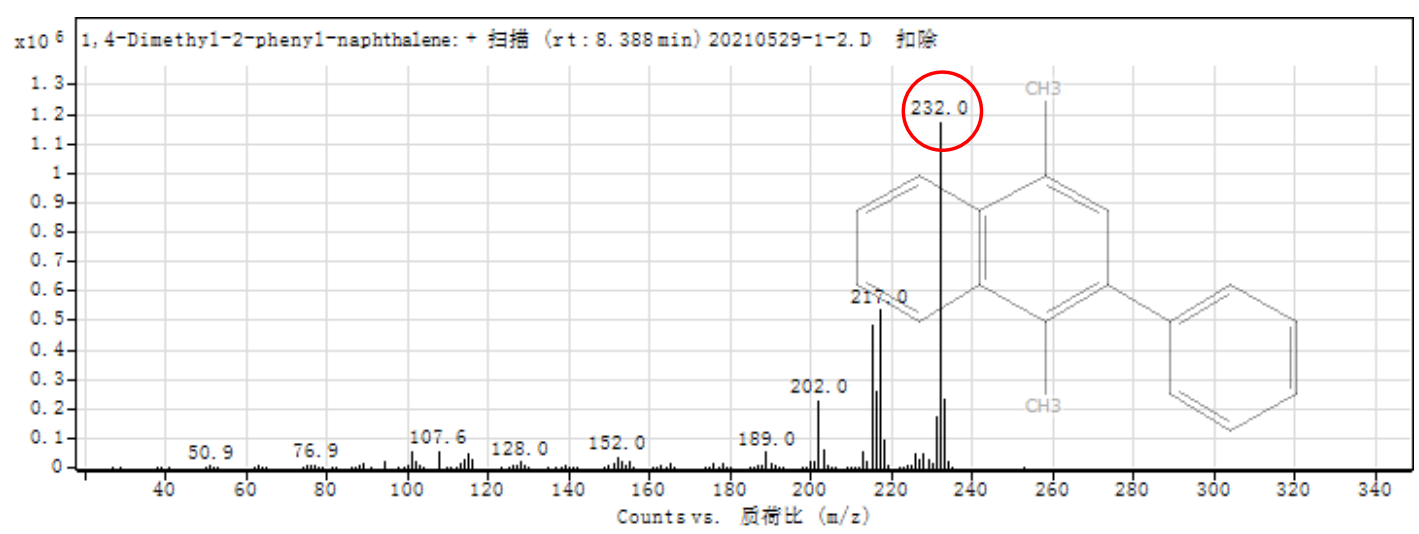

Figure S9. MS Spectrum of compound 3

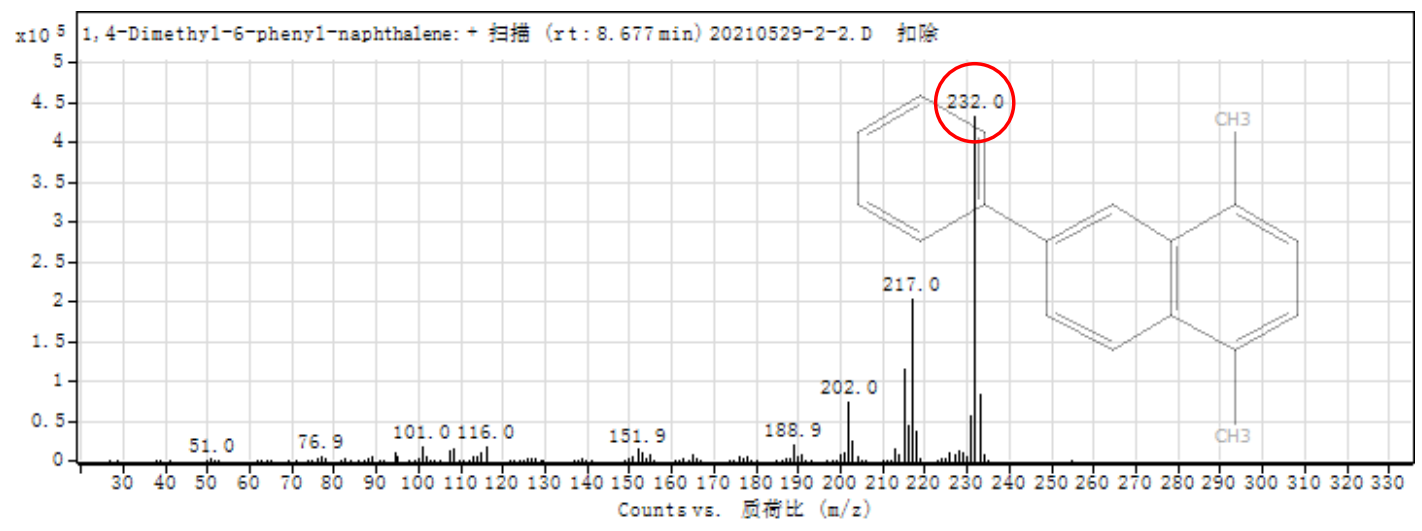

Figure S10. MS Spectrum of compound $\mathbf{6}$

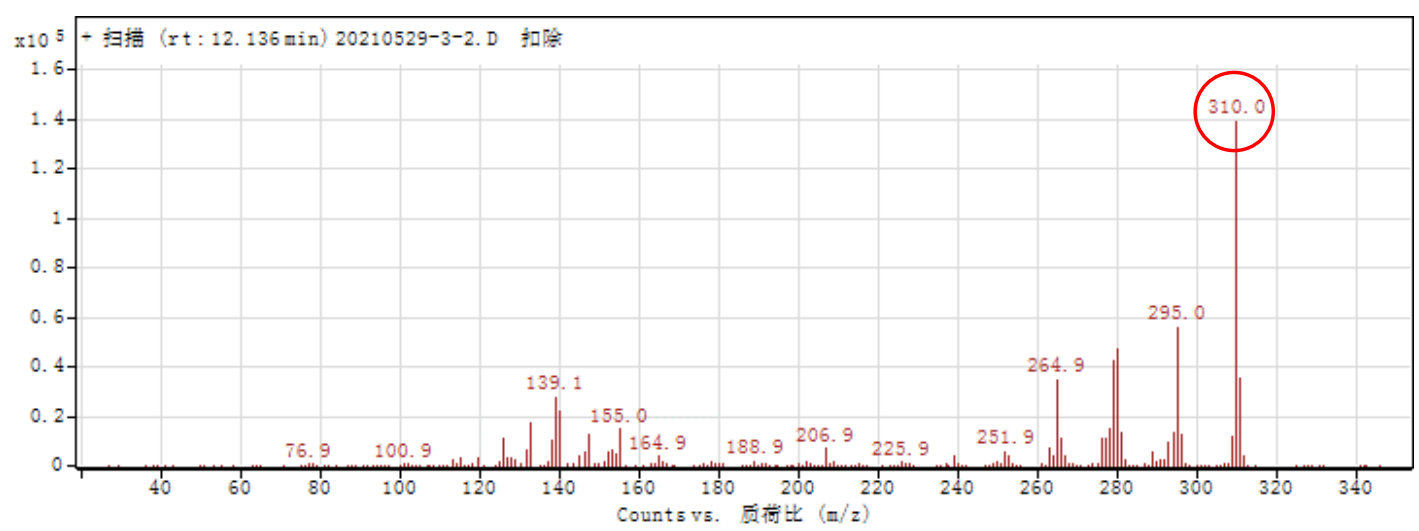

Figure S11. MS Spectrum of compound 8 
Time evolution of ${ }^{1} \mathrm{H}$ NMR spectra of compounds 4 and 7

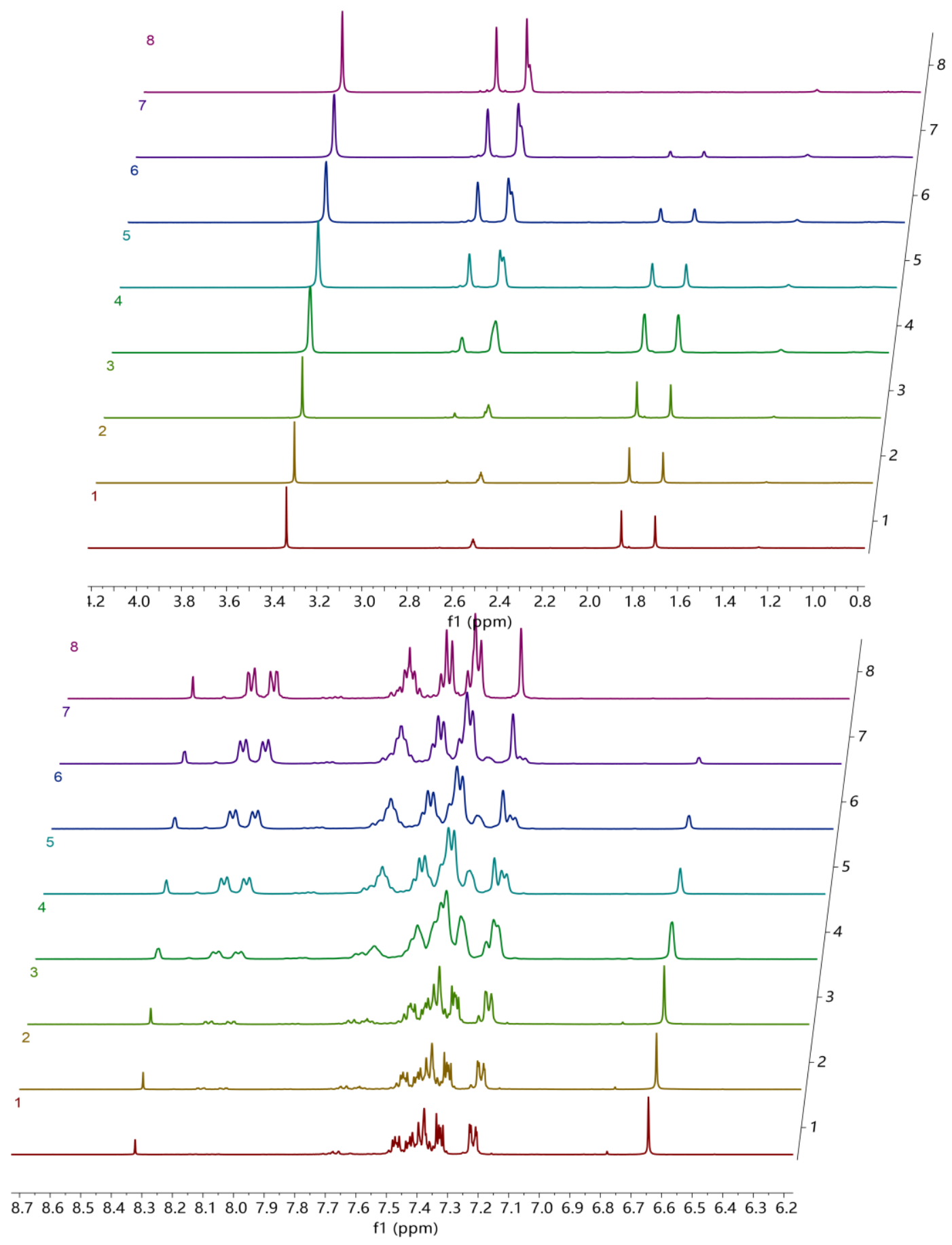

Figure S12. Time evolution of ${ }^{1} \mathrm{H}$ NMR spectra of compound 4 incubated in DMSO- $d_{6}$ at $37{ }^{\circ} \mathrm{C}$. Spectra 1- 0 h, Spectra 2- 0.5 h, Spectra 3- 1 h, Spectra 4- 2 h, Spectra 5- 4 h, Spectra 6- 6 h, Spectra 7- $9 \mathrm{~h}$, Spectra 8- $24 \mathrm{~h}$. Top: low field, bottom: high field. 


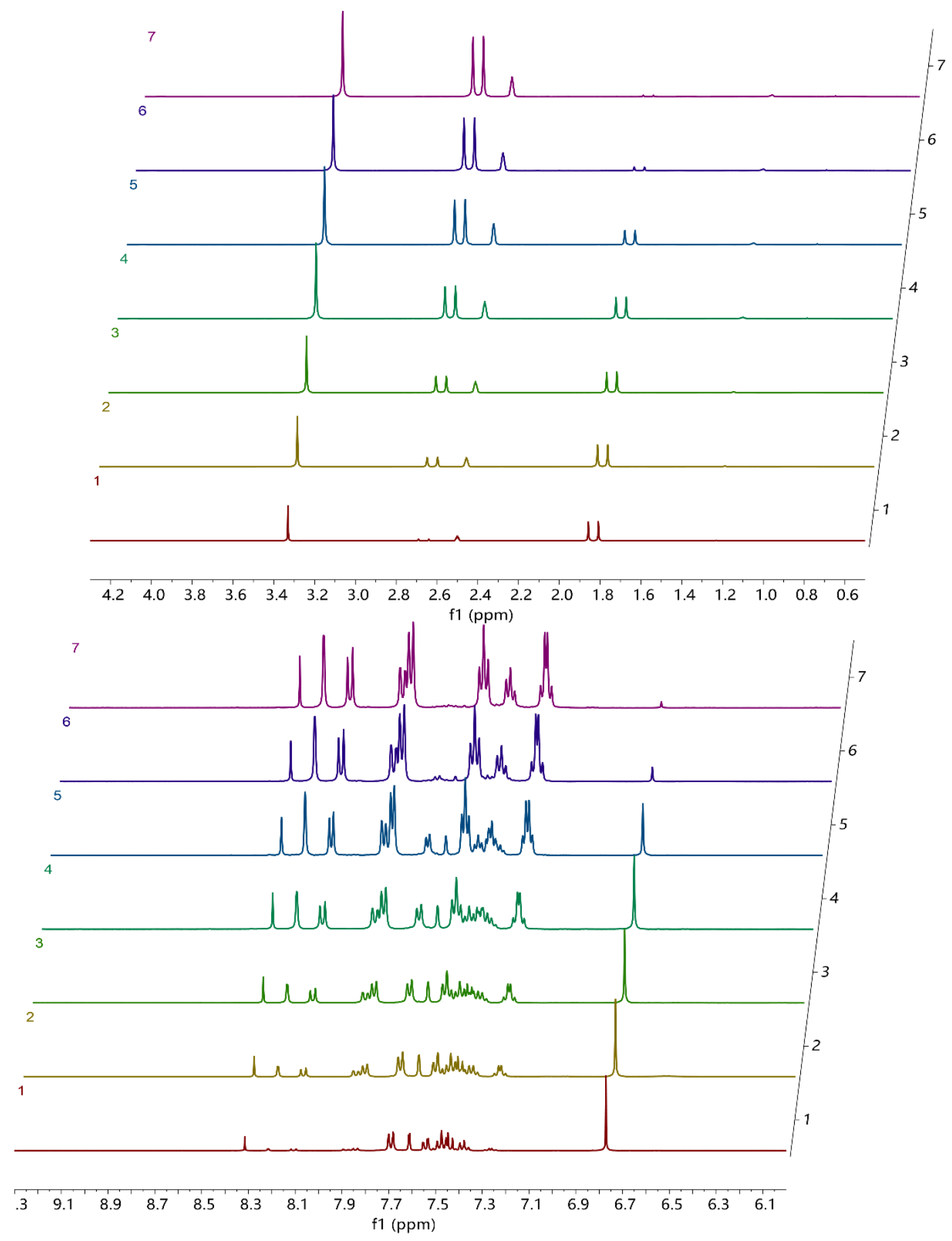

Figure S13. Time evolution of ${ }^{1} \mathrm{H}$ NMR spectra of compound 7 incubated in DMSO- $d_{6}$ at $37{ }^{\circ} \mathrm{C}$. Spectra 1- 0 h, Spectra 2- 0.5 h, Spectra 3- 1 h, Spectra 4- 1.5 h, Spectra 5- 2 h, Spectra 6- 3 h, Spectra 7- $4 \mathrm{~h}$. Top: low field, bottom: high field. 


\section{Rate calculations for figures 5 and 6.}

For the dimer 9 , the total rate of $\left[{ }^{1} \mathrm{O}_{2}\right]$ production as a function of time:

$\mathrm{d}\left[{ }^{1} \mathrm{O}_{2}\right] / \mathrm{dt}=\mathrm{k}_{1}[\mathbf{9 - 6 e n d o}]_{\mathrm{t}}+\mathrm{k}_{2}[\mathbf{9 - 2 e n d o}]_{\mathrm{t}}, \quad$ also $\quad[\mathbf{9 - 6 e n d o}]_{0}=[\mathbf{9}-2 \mathrm{endo}]_{0}$

$=\mathrm{k}_{1}[9-6 e n d o]_{0} \mathrm{e}^{-\mathrm{k}_{1} / \mathrm{t}}+\mathrm{k}_{2}[\mathbf{9}-2 \mathrm{endo}]_{0} \mathrm{e}^{-\mathrm{k}_{2} / \mathrm{t}}$

Let $[9-6 \mathrm{endo}]_{0}=[9-2 \mathrm{endo}]_{0}=1$ unit concentration,

$=\mathrm{k}_{1} \mathrm{e}^{-\mathrm{k}_{1} / \mathrm{t}}+\mathrm{k}_{2} \mathrm{e}^{-\mathrm{k}_{2} / \mathrm{t}}$

$=\left(\ln 2 / \tau_{1}\right) \mathrm{e}^{-\left(\ln 2 / \tau_{1}\right)}+\left(\ln 2 / \tau_{2}\right) \mathrm{e}^{-\left(\ln 2 / \tau_{2}\right)} \quad \tau_{1}=1.23 \mathrm{~h} \quad \tau_{2}=5.7 \mathrm{~h}$

If two modules were separate molecules, with concentrations to be set to 2 unit concentration for a fair comparison:

That is $[6 \mathrm{endo}]_{0}=[2 \mathrm{endo}]_{0}=2[9-6 \mathrm{endo}]_{0}=2[9-2 \mathrm{endo}]_{0}$

and again, let $\tau_{1}=1.23 \mathrm{~h}$ and $\tau_{2}=5.7 \mathrm{~h}$

in two different hypothetical monomeric compounds

$\mathrm{d}\left[{ }^{1} \mathrm{O}_{2}\right] / \mathrm{dt}=2 \mathrm{k}_{1} \mathrm{e}^{-\mathrm{k}_{1} / \mathrm{t}}$ for compound 7 -like endoperoxide

and

$d\left[{ }^{1} \mathrm{O}_{2}\right] / d t=2 k_{2} e^{-k_{2} / t}$ for compound 4-like endoperoxide

All three rates were plotted in figures 5 and 6 . 